\title{
An analysis of outcome of paediatric hydrocephalus: A 10 year study from Central India
}

\author{
*Roshan Chanchlani ${ }^{1}$, Reyaz Ahmed ${ }^{2}$, Amit Agarwal $^{3}$ \\ Sri Lanka Journal of Child Health, 2021; 50(3): 453-458
}

\begin{abstract}
Introduction: Ventriculo-peritoneal (VP) shunt is an easy and inexpensive procedure done for the management of hydrocephalus all over the world. However, it is associated with several complications and morbidity.
\end{abstract}

Objectives: To assess the outcome of children having hydrocephalus who underwent a VP shunt.

Method: In this retrospective study, records of 196 children who were operated on by the first author for hydrocephalus were analysed and the spectrum of complications noted. This ten year study was conducted from May 2010 to April 2020 and the patients were operated in various hospitals and tertiary care centres in Bhopal city, Madhya Pradesh, India.

Results: Out of the 196 patients, 120 were boys and 76 were girls. In this series $130(66.3 \%)$ patients were less than 1 year of age. Median age was 20.7 months (range 1.4 months to 9.5 years). Aqueductal stenosis (35.7\%) was the commonest congenital cause and tubercular meningitis $(16.3 \%)$ the commonest acquired cause of hydrocephalus. Vomiting (18.4\%) was the commonest symptom and enlargement of head $(40.8 \%)$ the commonest sign. Common indications for shunt revision were shunt obstruction (10.2\%) and shunt infection (6.6\%). Mortality in this series was $12.8 \%$.

Conclusions: Of the 196 children who underwent VP shunt for hydrocephalus over a period of 10 years, $12.8 \%$ died, $10.2 \%$ had shunt obstruction and $6.6 \%$ had shunt infection.

${ }^{1}$ Associate Professor, Department of Paediatric
Surgery, AIIMS, Bhopal, India, ${ }^{2}$ Associate
Professor, AIIMS, Bhopal, India, ${ }^{3}$ Associate
Professor, GM, Bhopal, India
*Correspondence: roshanchanchlani@gmail.com

iD https://orcid.org/0000-0002-8086-937 (Keceived on 14 August 2020: Accepted after revision on 18 September 2020)

The authors declare that there are no conflicts of interest

Personal funding was used for the project.

Open Access Article published under the Creative

Commons Attribution CC-BY (CC) (i) License
DOI: http://doi.org/10.4038/sljch.v50i3.9695

(Key words: Head circumference, paediatric hydrocephalus, VP shunt)

\section{Introduction}

With present day high standards of care, most patients operated for paediatric hydrocephalus survive but morbidity and mortality from hydrocephalus still exist ${ }^{1}$. Ventriculo-peritoneal (VP) shunt is the commonest surgery done for paediatric hydrocephalus ${ }^{2}$. Despite technical advances, shunt infection is yet a serious complication $^{3,4}$. Besides VP shunt, other shunting techniques for hydrocephalus are endoscopic third ventriculostomy, ventriculo-atrial shunts and lumbar-peritoneal shunts ${ }^{5}$.

\section{Objectives}

To assess the outcome of children having hydrocephalus who underwent a VP shunt.

\section{Method}

In this retrospective study, records of 196 children who were operated on by the first author for hydrocephalus in the paediatric age group were studied and the spectrum of complications noted. This ten year study was conducted from May 2010 to April 2020 and the patients were operated in various hospitals and tertiary care centres in Bhopal city, Madhya Pradesh, India.

Inclusion criteria: Patients 12 years of age and below, with a diagnosis of hydrocephalus were included.

Exclusion criteria: Patients over the age of 12 years, patients with intracranial space occupying lesions and those not giving consent for surgery were excluded.

On admission, demographic profile like age, sex, weight, head circumference, duration of symptoms and signs, were noted. Thorough clinical examination was done. General condition of patient was assessed and necessary radiological and laboratory investigations were done. Transfontanelle ultrasonography (USG), computed tomography (CT) and magnetic resonance imaging (MRI) were done to assess ventricular dilatation and parenchymal thickness.

After investigation, patients were subjected to VP shunt insertion under general anaesthesia. Thirdgeneration cephalosporins were given at the time of induction in all cases. After incision over sc alp, a 
small burr hole was made and the dura was incised with cautery and the fenestrated ventricular end was placed, in the lateral ventricle. A tunnel was made in the subcutaneous plane for shunt tube placement and distal end was placed in the suprahepatic space through a small transverse right upper quadrant incision. Upper end of the shunt tube was fixed to scalp layers with absorbable suture. Postoperatively, all patients were monitored in the paediatric intensive care unit (PICU) or neonatal intensive care unit (NICU). They were given intravenous (IV) fluids, antibiotics, and analgesics. The patients were discharged in five days if there were no complications.

The patients were followed up in the outpatient department (OPD) at various intervals up to one year after surgery. Milestones of development, convulsions, acceptance of feed, fever, signs of increased intracranial pressure were noted clinically on follow up. Function of VP shunt was checked by compressing and rapid refilling of the shunt chamber. Three months after surgery a follow up CT scan was done. Data were collected, analysed and compared with other available literature.

Ethical issues: As this was a retrospective observational study of records of operated patients available with the first author from various centres where he worked, no ethical clearance was obtained and informed consent was not a possibility. Confidentiality is ensured.

\section{Results}

In the ten year period, out of the 196 children operated, 120 were boys and 76 were girls, 130 $(66.3 \%)$ were less than 1 year of age and the median age was 20.7 months (range 1.4 months to 9.5 years)

Table 1 shows the causative factors for hydrocephalus. Aqueductal stenosis was the commonest congenital cause and tubercular meningitis the commonest acquired cause of hydrocephalus.

Table 1: Causative factors for hydrocephalus

\begin{tabular}{|l|c|}
\hline \multicolumn{1}{|c|}{ Causative factor } & Number (\%) \\
\hline Congenital & $70(35.7)$ \\
\hline Aqueductal stenosis & $12(06.1)$ \\
\hline Dandy Walker syndrome & $12(06.1)$ \\
\hline Arnold Chiari malformation & $30(15.3)$ \\
\hline $\begin{array}{l}\text { Lumbosacral } \\
\text { meningomyelocoele }\end{array}$ & $06(03.1)$ \\
\hline Occipital encephalocoele & $32(16.3)$ \\
\hline Acquired & $26(13.3)$ \\
\hline Tubercular & $04(02.1)$ \\
\hline Pyogenic & $04(02.1)$ \\
\hline Post traumatic & $196(100.0)$ \\
\hline Ventricular haemorrhage
\end{tabular}

The symptoms of hydrocephalus are shown in Table 2. Vomiting and headache were the most common symptoms.

Table 2: Symptoms of hydrocephalus

\begin{tabular}{|l|c|}
\hline \multicolumn{1}{|c|}{ Symptom } & Number (\%) \\
\hline Asymptomatic & $66(33.7)$ \\
\hline Vomiting & $36(18.4)$ \\
\hline Headache & $34(17.3)$ \\
\hline Fever & $22(11.2)$ \\
\hline Convulsions & $14(07.1)$ \\
\hline Dull and Drowsy & $12(06.1)$ \\
\hline Irritability & $12(06.1)$ \\
\hline Total & $196(100.0)$ \\
\hline
\end{tabular}

The signs of hydrocephalus are shown in Table 3. Enlargement of head was the most common sign.

Table 3: Signs of hydrocephalus

\begin{tabular}{|l|c|}
\hline \multicolumn{1}{|c|}{ Signs } & Number (\%) \\
\hline Raised head circumference & $80(40.8)$ \\
\hline $\begin{array}{l}\text { Wide and deformed cranial } \\
\text { sutures }\end{array}$ & $40(20.4)$ \\
\hline Papilloedema & $30(15.3)$ \\
\hline Bulging anterior fontanelle & $28(14.3)$ \\
\hline $\begin{array}{l}\text { Deranged higher mental } \\
\text { functions }\end{array}$ & $18(09.2)$ \\
\hline Total & $196(100.0)$ \\
\hline
\end{tabular}

Complications of VP shunts requiring revision are shown in Table 4.

Table 4: Complications of ventriculo-peritoneal shunts requiring revision $(n=196)$

\begin{tabular}{|l|c|}
\hline \multicolumn{1}{|c|}{ Causes } & n (\%) \\
\hline Peritoneal end block/ malfunction & $17(08.7)$ \\
\hline Shunt tract infection & $13(06.6)$ \\
\hline Ventricular end block/ malfunction & $03(01.5)$ \\
\hline CSF leak from wound & $02(01.0)$ \\
\hline Anal protrusion of shunt & $02(01.0)$ \\
\hline CSF pseudocyst & $02(01.0)$ \\
\hline Displaced ventricular end & $01(0.5)$ \\
\hline Extrusion from neck & $01(0.5)$ \\
\hline Extrusion from abdominal incision & $01(0.5)$ \\
\hline Total & $42(21.4)$ \\
\hline
\end{tabular}

CSF: Cerebrospinal fluid

The most common indications of shunt revision were shunt obstruction comprising 20 (10.2\%) cases and shunt infection comprising 13 (6.6\%) cases. There were 2 cases of cerebrospinal fluid (CSF) leak from abdominal wound following VP shunting and both were managed successfully by revision of the peritoneal part of shunt. Two cases presented as extrusion of peritoneal part of VP shunt catheter through the anus without features of peritonitis or meningitis (Figure 1). This was managed by a mini laparotomy with revision of the peritoneal part of shunt alone. 


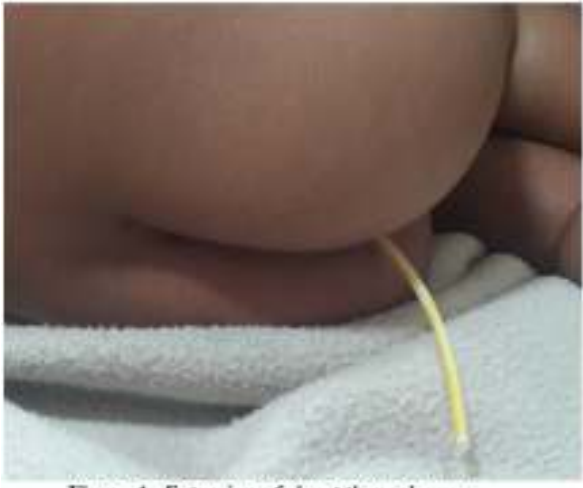

Figure 1: Evtrusion of shount through anus

We observed two cases of CSF pseudocysts in the peritoneal cavity following VP shunt operations (Figure 2), both presenting with progressive abdominal distention and malfunction of the peritoneal part of the shunt.. Both were managed by formal exploratory laparotomy, excision of the cysts and relocation of the peritoneal catheter.

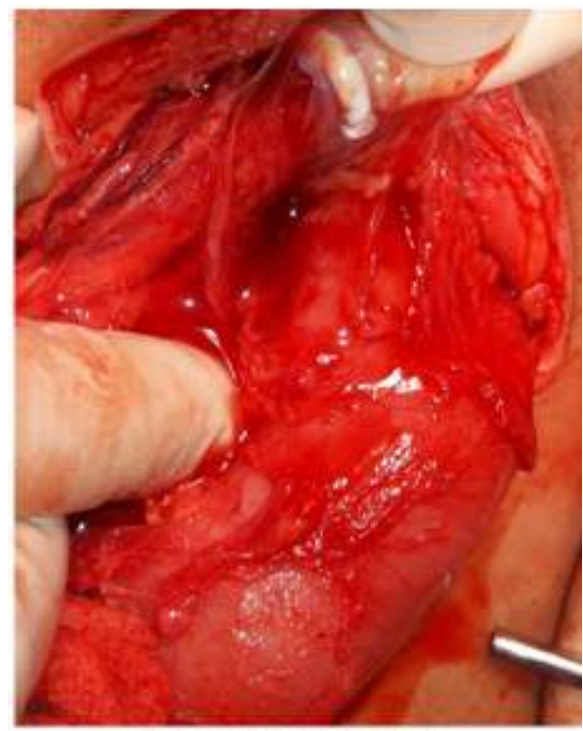

Figure 2: CSF pseudocyst

Complications of VP shunts which did not require revision are shown in Table 5.

Table 5: Complications of ventriculo-peritoneal shunts not requiring revision of shunt $(n=196)$

\begin{tabular}{|l|c|}
\hline Causes & Number (\%) \\
\hline Seizure & $14(07.1)$ \\
\hline Superficial wound infection & $04(02.0)$ \\
\hline Ascites & $04(02.0)$ \\
\hline Craniosynostosis & $02(01.0)$ \\
\hline Subgaleal collection & $02(01.0)$ \\
\hline Inguinal hernia & $02(01.0)$ \\
\hline Hydrocoele & $02(01.0)$ \\
\hline Total & $30(15.3)$ \\
\hline
\end{tabular}

There were 2 cases of inguinal hernia after VP shunts related to an accumulation of CSF in excess of the peritoneal absorption rate. Two cases of subgaleal fluid accumulation after shunt surgery were seen in this study (Figure 3).

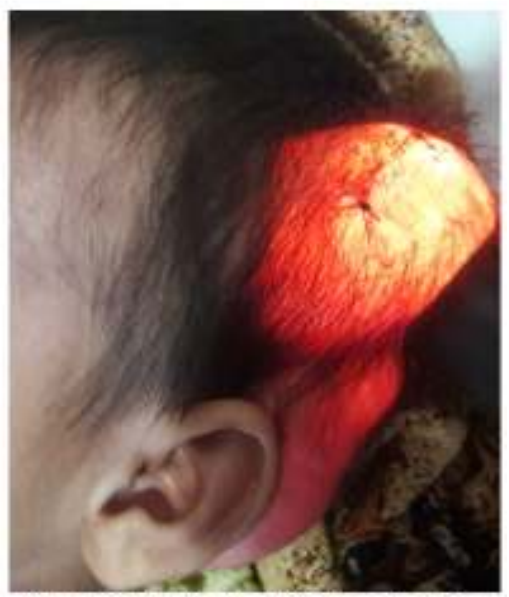

Figure 3: Subgaleal CSF collection

We also encountered extrusion of the peritoneal part of the VP shunt catheter, one each from neck wound (Figure 4) and from the abdominal wound (Figure5). In both cases disconnection of tube was done from shunt chamber under local anaesthesia and distal tubing was pulled out. Reshunting on opposite side was done later.
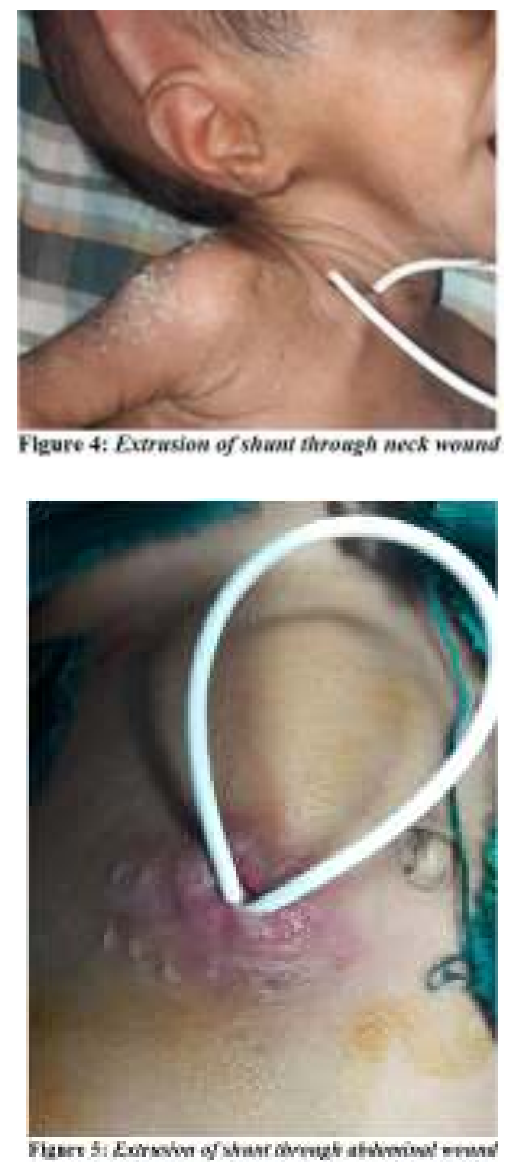

In this study two cases of craniosynostosis were seen (Figure 6). 


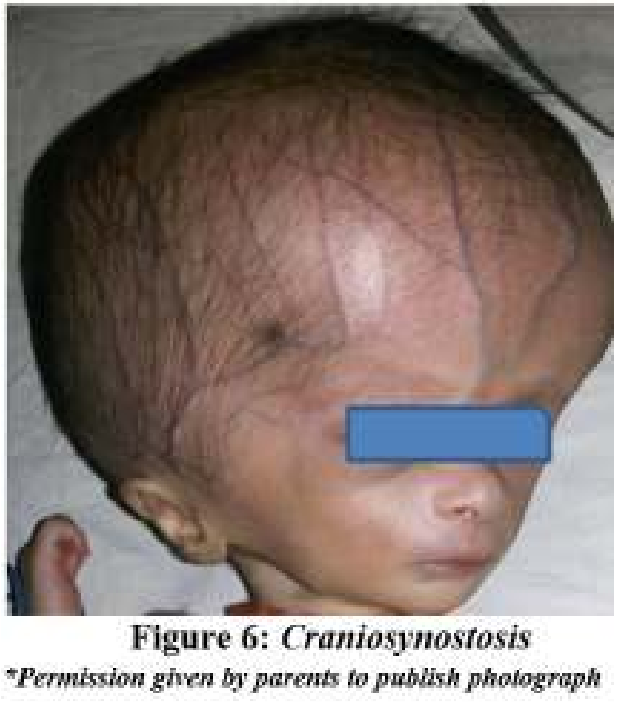

Mortality in this study was $12.8 \%$ (25 out of 196$)$.

\begin{abstract}
Discussion
Hydrocephalus is the pathological accumulation of intracranial CSF due to overproduction or decreased circulation to other brain compartments leading to swelling of the ventricular system and ultimately to brain damage ${ }^{6,7}$. The commonest causes of shunt failure in children are obstruction and infection ${ }^{8}$. In this study, overall complications of VP shunt in congenital hydrocephalus was 72 (36.7\%), which is in accordance with global figures of $25-40 \%{ }^{3,9,10}$. The incidence of shunt blockage has been reported in the literature to range from $5 \%$ to $47 \%{ }^{11,12}$. In this series the incidence of shunt blockage was $10.2 \%$.
\end{abstract}

In this study, infection was the second common complication following shunt surgery with an incidence of $6.6 \%$. In various studies $40 \%$ of shunt infections are due to Staphylococcus epidermidis and $20 \%$ to Staphylococcus aureus ${ }^{13}$. Because these organisms form a part of the normal skin flora, endogenous spread from patient or staff is the probable route of infection ${ }^{14}$. Shunt infection was treated by intermittent CSF tapping and IV antibiotics based on culture and sensitivity of CSF and exteriorization of the shunt. Revision of shunt was done only when CSF samples confirmed absence of infection. Choux $\mathrm{M}$, et $a l^{15}$ showed that better selection of indications, adequate skin preparation with disinfecting baths and a standardized surgical technique greatly reduced the infection level. Premature neonates are at the greatest risk for shunt infection as their immune system is not fully developed ${ }^{16}$. Rotim $\mathrm{K}$, et $a l^{17}$ adopting a strict protocol for shunt placement, including adequate skin preparation, perioperative antibiotics, and short operating time, reduced their rate of shunt infection from $17.9 \%$ to $8 \%$.
In our study two cases presented as extrusion of the peritoneal part of VP shunt catheter through the anus without features of peritonitis or meningitis. Perforation of bowel by catheter tubing is a rare complication of VP shunt placement carrying the risk of ascending infection to the brain in the form of meningitis, encephalitis, or brain abscess $^{18}$. We observed two cases of CSF pseudocysts in peritoneal cavity following VP shunt operations, both presenting with progressive abdominal distention and malfunction of the peritoneal part of the shunt. CSF pseudocysts in the peritoneal cavity is a known complication of VP shunt malfunction with an incidence of $<1 \%$ to $4.5 \%{ }^{19,20}$. USG and CT scan of abdomen and pelvis are excellent imaging modalities for diagnosis of CSF pseudocysts. The treatment options for CSF pseudocysts in the peritoneal cavity are excision of the cysts and relocation of the shunt that can be done either through formal laparotomy or laparoscopically ${ }^{21,22}$. Two cases of subgaleal fluid accumulation after shunt surgery were seen in this study. Various studies have described this complication mostly with malfunctioning shunt in the early post-operative period ${ }^{23,24}$. We also encountered extrusion of the peritoneal part of the VP shunt catheter, one each from the neck wound and the abdominal wound. In this study two cases of craniosynostosis were seen. Hydrocephalus is found in $4-10 \%$ of cases of craniosynostosis ${ }^{25}$.

Although the risk in performing shunt operation is low, the complications related to shunts are many and in this study $20(47.6 \%)$ of the failures were seen within three months of surgery. Several reports have mentioned that $40-60 \%$ of shunt infections manifest within three months after shunt insertion ${ }^{26}$. In this study there were $25(12.8 \%)$ deaths and the mortality reported in various studies was around $13.7 \%{ }^{27}$. Endoscopic third ventriculostomy obviates the need for a ventricular shunt, thus avoiding shunt-related complications $^{28}$. CSF shunting has a propensity for mechanical failure and children with VP shunts should be regularly followed-up through transition to adulthood.

\section{References}

1. Acakpo-Satchivi L, Shannon CN, Tubbs RS, Wellons JC, Blount JP, Iskandar BJ, et al. Death in shunted hydrocephalic children: a follow-up study. Childs Nervous System 2008; 24(24): 197-201. https://doi.org/10.1007/s00381-007-04084

PMid: 17594102 
2. Ghritlaharey RK, Budhwani KS, Shrivastava DK, Gupta G, Kushwaha AS, Chanchlani $\mathrm{R}$, et al. Trans-anal protrusion of ventriculo-peritoneal shunt catheter with silent bowel perforation: Report of ten cases in children. Pediatric Surgery International 2007; 23: 575-80. https://doi.org/10.1007/s00383-007-19168

PMid: 17387494

3. Reddy GK, Bollam P, Caldito G. Longterm outcomes of ventriculo-peritoneal shunt surgery in patients with hydrocephalus. World Neurosurgery 2014; 81: 404-10.

https://doi.org/10.1016/j.wneu.2013.01.09 6

PMid: 23380280

4. Simon TD, Butler J, Whitlock KB, Browd $\mathrm{SR}$, Holubkov R, Kestle JR, et al. Hydrocephalus Clinical Research. Risk factors for first cerebrospinal fluid shunt infection: findings from a multi-centre prospective cohort study. Journal of Pediatrics 2014; 164:1462-8. https://doi.org/10.1016/j.jpeds.2014.02.01 3

PMid: 24661340 PMCid: PMC4035376

5. Yadav YR, Parihar V, Sinha M. Lumbar peritoneal shunt. Neurology India 2010; 58: $179-84$.

https://doi.org/10.4103/0028-3886.63778

PMid: 20508332

6. Grover S, Menon P, Samujh R, Rao KL. Congenital hydrocephalus: A comparative study on the efficacy and complications after low versus medium pressure ventriculoperitoneal shunts. Journal of the Indian Association of Pediatric Surgeons 2004; 9:143-7.

7. Ahmed A, Sandlas G, Kothari P, Sarda D, Gupta A, Karkera P, et al. Outcome analysis of shunt surgery in hydrocephalus. Journal of the Indian Association of Pediatric Surgeons 2009; 14: 98-101.

https://doi.org/10.4103/0971-9261.57700

PMid: 20376249 PMCid: PMC2847144

8. McGirt MJ, Leveque J, Wellons JC, Villavicencio AT, Hopkins JS, Fuchs HE. Cerebrospinal fluid shunt survival and aetiology of failures: a seven year institutional experience Pediatric Neurosurgery 2002; 36: 248-55. https://doi.org/10.1159/000058428

PMid: 12053043

9. Tully HM, Dobyns WB. Infantile hydrocephalus: a review of epidemiology, classification and causes. European Journal of Medical Genetics 2014; 57(8): 359-68.

https://doi.org/10.1016/j.ejmg.2014.06.00 2

PMid: 24932902 PMCid: PMC4334358

10. Riva-Cambrin J, Kestle JR, Holubkov R, Butler J, Kulkarni AV, Drake J, et al. Hydrocephalus Clinical Research Network. Risk factors for shunt malfunction in paediatric hydrocephalus: a multicentre prospective cohort study. Journal of Neurosurgery- Pediatrics 2016; 17(4): 382-90. https://doi.org/10.3171/2015.6.PEDS1467 0

PMid: 26636251

11. Tyagi DK, Balasubramaniam S, Jayaswal SA, Savant HV, Gandhi AS. Outcome analysis of ventriculo-peritoneal shunt procedures in hydrocephalus due to tubercular meningitis and non-infective cases. International Journal of Contemporary Pediatrics 2016; 13: 12105.

https://doi.org/10.18203/23493291.ijcp20 162788

12. Kinasha AD, Kahamba JF, Semali IT. Complications of ventriculo-peritoneal shunts in children in Dar es Salaam. East Central African Journal of Surgery 2005; 10: 55-9.

13. Braga MH, Carvalho GTC, Brando RACS, Lima FBF, Costa BS. Early shunt complications in 46 children with hydrocephalus. Arq Neuro-Psiquiatr 2009; 13: 145-8. https://doi.org/10.1590/S0004282X20090 00200019

PMid: 19547822

14. Bayston R, Ashraf W, Bhundia C. Mode of action of an antimicrobial biomaterial for use in hydrocephalus shunts. Journal of Antimicrobial Chemotherapy 2004; 53(5): 778-82.

https://doi.org/10.1093/jac/dkh183

PMid: 15056650 
15. Choux M, Genitori L, Lang D, Lena G. Shunt implantation: reducing the incidence of shunt infection. Journal of Neurosurgery 1992; 77: 875-80.

https://doi.org/10.3171/jns.1992.77.6.0875 PMid: 1432129

16. Simon TD, Hall M, RivaCambrin J, Albert JE, Jefferies HE, LaFleur $\mathrm{B}$, et al. Infection rates following initial cerebrospinal fluent shunt placement across paediatric hospitals in the United States. Journal of NeurosurgeryPediatrics 2009; 4: 156-65. https://doi.org/10.3171/2009.3.PEDS0821 5

PMid: 19645551 PMCid: PMC2896258

17. Rotim K, Miklic P, Paladino J, Melada A, Marcikic M, Scap M. Reducing the incidence of infection in paediatric cerebrospinal fluid shunt operations Childs Nervous System 1997; 13: 584-7. https://doi.org/10.1007/s003810050144 PMid: 9454973

18. Ibrahim AW. E. coli meningitis as an indicator of intestinal perforation by V-P shunt tube. Neurosurgery Review 1998; 21: 194-7.

https://doi.org/10.1007/BF02389332

PMid: 9795961

19. Yuh SJ, Vassilyadi M. Management of abdominal pseudocyst in shunt-dependent hydrocephalus. Surgery International 2012; 3: 146. https://doi.org/10.4103/2152-7806.103890 PMid: 23230527 PMCid: PMC3515935

20. Mobley LW, Doran SE, Hellbusch LC. Abdominal pseudocyst: Predisposing factors and treatment algorithm. Pediatric Neurosurgery 2005; 41: 77-83. https://doi.org/10.1159/000085160 PMid: 15942277

21. Pseudocysts of the abdomen associated with ventriculo-peritoneal shunts: a report of twelve cases and a review of the literature. Pediatric Neuroscience 1989; 15: $23-7$.

https://doi.org/10.1159/000120436

PMid: 2699757

22. Kariyattil R, Steinbok P, Singhal A, Cochrane DD. Ascites and abdominal pseudocysts following ventriculoperitoneal shunt surgery: variations of the same theme. Journal of Neurosurgery 2007; 106(5 suppl.): 350-3. https://doi.org/10.3171/ped.2007.106.5.35 0

PMid: 17566200

23. Schmitt CP, Dötschmann R, Daschner M, Zimmering M, Greiner C, Böswald M, et al. Residual peritoneal volume and body size in children on peritoneal dialysis. [Members of the Mid European Pediatric Peritoneal Dialysis Study Group (MEPPS)]. Advances in Peritoneal Dialysis 1999; 15: 287-90.

24. Aoki N. Lumbo-peritoneal shunt for the treatment of post-operative persistent collection of subcutaneous CSF (pseudomeningocoele). Acta Neurochir 1989; 98: 32-4.

https://doi.org/10.1007/BF01407173 PMid: 2741733

25. Fishman MA, Hogan GR, Dodge PR. The concurrence of hydrocephalus and craniosynostosis. Journal of Neurosurgery 1971; 34: 621-9, https://doi.org/10.3171/jns.1971.34.5.0621 PMid: 4326640

26. Gupta DK, Dave S. Hydrocephalus, test book of neonatal surgery. In: Gupta DK, editor. New Delhi: Modern Publishers; 2000. p. 434-50.

27. Tuli S, Tuli J, Drake J, Spears J. Predictors of death in paediatric patients requiring cerebrospinal fluid shunts. Journal of Neurosurgery 2004; 100: 4424.

https://doi.org/10.3171/ped.2004.100.5.04 42

PMid: 15287452

28. Ray P, Jallo GI, Kim RY, Kim BS, Wilson S, Kothbauer K, et al. Endoscopic third ventriculostomy for tumour-related hydrocephalus in a paediatric population. Neurosurgery Focus 2005; 19: E8. https://doi.org/10.3171/foc.2005.19.6.9 PMid: 16398485 